\title{
A study of chronic pelvic pain after radiotherapy in survivors of locally advanced cervical cancer
}

\author{
Ingvild Vistad • Milada Cvancarova • \\ Gunnar Balle Kristensen • Sophie Dorothea Fosså
}

Received: 20 October 2010 / Accepted: 9 January 2011 / Published online: 23 January 2011

(C) The Author(s) 2011. This article is published with open access at Springerlink.com

\begin{abstract}
Introduction Chronic pelvic pain (persisting pain in hips, groins or lower back) is poorly described in studies of cervical cancer survivors (CCSs). The aims of this study were to describe chronic pelvic pain and associated variables in CCSs surveyed $>5$ years post-radiotherapy, and to compare the presence of pain in hips and lower back in CCSs with findings in the general female population. Methods Ninety-one CCSs treated with radiotherapy between 1994 and 1999 were in 2005 included in a crosssectional questionnaire-based study. They were asked about demographic variables, clinical symptoms, mental distress,
\end{abstract}

I. Vistad $(\triangle)$

Department of Gynaecology, Sorlandet Hospital HF,

Service Box 416,

4604, Kristiansand, Norway

e-mail: ingvild.vistad@sshf.no

M. Cvancarova $\cdot$ S. D. Fosså

National Resource Center for Late Effects,

Department of Oncology, Oslo University Hospital,

Oslo, Norway

M. Cvancarova $\cdot$ S. D. Fosså

University of Oslo,

Oslo, Norway

G. B. Kristensen

Department of Gynaecological Oncology, the Radium Hospital, Oslo University Hospital,

Oslo, Norway

\section{G. B. Kristensen}

Department of Medical Informatics, the Radium Hospital, Oslo University Hospital,

Oslo, Norway and quality of life (QOL). Normative data (NORM) were collected from a population-study of Norwegian females. Results Pain in lower back and hips was significantly more prevalent $(p<.001)$ in CCSs compared to NORMs. 35/92 (38\%) of the CCSs had chronic pelvic pain. These women had significantly lower QOL, higher levels of anxiety and depression and more bladder and intestinal problems than those without chronic pelvic pain. In a multivariable regression model, use of analgesics and intestinal and bladder problems were significantly associated with chronic pelvic pain in the CCSs.

Conclusions CCSs have a higher prevalence of pain in lower back and hips than women in the general population, which might be due to late effects of radiation. 35/92 (38\%) of the CCSs suffer from chronic pelvic pain, shown to be associated with high overall mental and somatic morbidity. Implications for Cancer Survivors Evaluation and management of pelvic pain is important in follow-up of CCSs treated with radiotherapy.

Keywords Pelvic pain · Cervical cancer

Radiation therapy $\cdot$ Long-term survivors

\section{Introduction}

Chronic pain is a frequent complication of cancer and its treatment, and is often underreported and poorly described [1]. Few studies have investigated chronic pelvic pain (here defined as pain that persists longer than the time of natural healing located in hips, groins, lower back, radiating pain, pain in rest or activity and/or pain influencing daily activities) in long-term cervical cancer survivors (CCSs) after radiotherapy. Studies on chronic 
pelvic pain in CCSs have mainly focused on insufficiency fractures [2-4], chronic radiation enteritis, proctitis, and cystitis usually reported by physicians [5-8]. Other painful complications of pelvic radiation are lumbosacral plexopathies, chronic radiation myelopathy, lymphedema pain, burning perineum syndrome, and osteoradionecrosis [9]. Rarely, patients suffer from chronic pelvic pain without obvious pathology [10]. However, this diagnosis should only be considered if the patient's symptoms are not due to a gynaecological cause. In clinical practice, it is important to identify patients who suffer from treatmentrelated pain, and a case finding instrument could be useful for this purpose. However, such instruments are not available at present, and in the majority of studies on self-reported morbidity, pain is just rated as a single item on a symptom-list, usually referring to back pain.

Pain has been shown to be associated with anxiety, depression, and reduced quality of life (QOL) in cancer survivors of various diagnoses, as well as in palliative cancer patients [5, 11-15]. There is, however, limited knowledge regarding such associations in CCSs after radiotherapy.

Self-reported pain in the hips and the lower back is common in the general female population. Some studies show similar or even lower prevalence of such pain in CCSs compared to healthy controls [16-19]. However, these studies are based on small patient samples [17, 18], often lack a clear definition of pain [16], or have included patients with a mixture of gynaecological diagnoses and treatment modalities [19].

On this background, the first aim of this study was to describe chronic pelvic pain in CCSs and to explore the differences between CCSs with and without chronic pelvic pain regarding somatic morbidity in the pelvic organs, as well as anxiety, depression, and QOL. Secondly, we wanted to assess the strength of the associations between relevant independent variables and chronic pelvic pain in CCSs adjusted for possible confounders. Thirdly, we aimed to investigate the prevalence of pain in hips and lower back in CCSs after radiotherapy compared to the prevalence in the general female population.

\section{Patients and methods}

Patients and treatment

From 1994 to 1999, almost all patients with cervical cancer stage Ib2-IVa referred to The Radium Hospital and treated with a curative intent were included in a prospective Nordic Cervical Cancer Study (NOCECA). The patients in NOCECA received external beam radiotherapy (EBRT) to the pelvis and intra-cavitary radiotherapy (ICRT), as described previously [6]. Briefly, for patients with tumours $\leq 8 \mathrm{~cm}$ (mostly stage Ib2 and IIb) the treatment consisted of $50-45$ Gy in 25 fractions through anterior-posterior/ posterior-anterior (AP-PA) pelvic fields (Type 1) with a treatment time of 6 weeks. In patients with tumours $>8 \mathrm{~cm}$ (mostly stage IIIb) the dose could optionally be raised to $60 \mathrm{~Gy}$ with an additional $10 \mathrm{~Gy}$ in five fractions with lateral fields, extending the treatment time to 7 weeks (Type 2). Extended radiation fields were given to patients with enlarged para-aortic lymph nodes on MRI and proven metastasis by image-guided biopsy ( $50.4 \mathrm{~Gy} / 28)$. The dose contribution to the bony structures of the pelvis was mainly from the EBRT and varied according to the individual position of the external fields. For the bony structures encompassed by the AP-PA-fields, the dose varied from 45 Gy to 50 Gy for Type 1 patients, and from 45 Gy to 60 Gy for Type 2 patients. The rest of the bony structures received an estimated dose of 5-45 Gy.

ICRT was interposed during the external radiation course. Point A was defined on the X-ray as being $2 \mathrm{~cm}$ superior to the vaginal sources and $2 \mathrm{~cm}$ lateral to the cervical canal. ICRT was performed with a standard prescribed dose to Point A of 4.2 Gy per fraction.

No chemotherapy was given to these patients.

\section{Selected patients}

Of the 381 patients included in NOCECA, 147 (39\%) were alive on January 1, 2005. These women received a mailed invitation to take part in the study and a questionnaire covering somatic impairments and QOL as well as demography, comorbidity and life-style issues. Nonresponders received a written reminder after 3 weeks. Details regarding diagnosis and treatment were retrieved from the NOCECA clinical database.

\section{Measures}

\section{Pain-definitions}

Chronic pelvic pain was covered by seven self-made items including pain in hips, groins, lower back, radiating pain, pain in rest or activity, and pain influencing daily activities (Table 2). The questions were not validated, however, our clinical experience is that the items reflect important aspects of pelvic pain to the patients. In this study, the Chronbach's alpha for the seven-item pain scale was $\alpha=.91$. In addition, there was a highly significant association between the seven self-made items and the bodily pain scale of the MOS Short Form-36 (SF-36). The items had the following possible answers: "No/none", "Monthly", "Weekly", "Daily", and "Constantly". Each response was dichotomised as "no pain' (no pain-monthly pain) or 'pain' (pain weekly-constantly), 
and then summed up to give totals ranging from 0 (no pain) to 7 (maximum pain). Caseness of chronic pelvic pain was defined as a sum score $\geq 2$.

Pains in hips and lower back during a previous month were scored as single items and dichotomised (pain or no pain previous month). Daily pain was defined as pain in hips and lower back 30 or 31 days during the previous month. The items on pain in hips and lower back are similar to the corresponding HUNT-2 questions. Therefore, we were able to use the items in both questionnaires and compare the answers from the patients with a healthy control group.

\section{Bladder and intestinal problems}

We used the Late Effects Normal Tissues-Subjective, Objective, Management, Analytic (LENT-SOMA) subjective scale for bladder and intestinal symptoms [20]. The LENT-SOMA is a self-rating instrument for measuring late somatic impairment/problems after radiotherapy. The LENT-SOMA scales have recently been incorporated into the National Cancer Institute (NCI) Common Terminology Criteria for Adverse Events (CTCAE). Severe bladder and intestinal problems were operationalised according to Vistad et al. [6], and here defined as severe self-reported problems in at least one of these organs. Briefly explained, the patients were classified as having severe problems when they scored as having problems daily or constantly in five of six intestinal items (e.g. Do you have any difficulty in controlling your bowels) or five of five bladder items (e.g. Do you suffer with incontinence of urine) [6]. Chronbach's alpha for the bladder scale was $\alpha=0,70$ and for the intestinal scale, $\alpha=0,82$.

\section{Anxiety and depression}

The Hospital Anxiety and Depression Scale (HADS) [21] consists of 14 items, 7 from the depression subscale (HADS-D) and 7 from the anxiety subscale (HADS-A). Cases of clinically significant anxiety disorder or depression are defined with a score of $\geq 8$ on HADS-A or HADS-D [22]. The HADS has shown excellent reliability coefficients and psychometric properties in numerous studies. For the CCSs in this study, Chronbach's alphas were $\alpha=0,89$ (HADS-A) and $\alpha=0,85$ (HADS-D).

\section{Physical and mental $Q O L$}

The SF-36 was used to assess QOL. The SF-36 [23] is a generic QOL questionnaire that consists of 36 items across eight dimensions covering physical and mental QOL. Each scale is scored from 0 to 100 , with higher values indicating more favourable QOL status. The dimensions can be summarized as the Physical and Mental Component Sum- mary Scales (PCS and MCS). The scales are calibrated so that the value of 50 refers to the mean of Norwegian normal population.

\section{Other variables}

Patients and controls were asked about mental problems resulting in reduced daily activities of $>1$ year duration (long-term mental complains), about daily smoking (yes/ no), and if they have a partner (yes/no). Further, they were asked about daily use of any drugs (yes/no), and of analgesics (yes/no). Three variables regarding the use of hypnotics, anxiolytics, or antidepressants were combined in the variable named psychotropics and rated as 'yes' if at least one of these drugs were used daily. Educational level was encoded based on the highest completed level of basic education as three categories: compulsory school ( $<9$ years), high school (10-12 years), and college/ university level ( $\geq 13$ years). Activities of daily living were defined as personal care activities necessary for everyday living.

\section{NORMs}

In the Health Study of Nord-Trøndelag County in 1995-97 (HUNT-2) [24] 35.280 women aged $\geq 20$ years participated (compliance rate $76 \%$ ) and filled in a questionnaire containing physical health among many other topics. Of these women, 33.054 had not been treated for cancer according to self-report, and represented the normative control sample (NORMs).

In HUNT-2, invitations were sent by mail along with questionnaire 1 , which was to be returned when the women came to the screening station. Questionnaire 1 contained questions about demography and long-term mental complaints. At the screening station all the participants received questionnaire 2 which was to be filled in at home and returned by mail. Items about pain in hips and lower back in addition to use of drugs were included in questionnaire 2.

We have no normative controls for the cancer-specific LENT SOMA-questionnaire.

\section{Ethics}

The study was approved by the institutional and regional Committee for Ethics in Medical Research, Region South and by the National Data Inspectorate of Norway. Every patient gave written informed consent.

Data management and statistics

Data were described with proportions for categorical variables and with median and ranges for continuous variables. Crude 
associations between categorical data were assessed with chisquare tests and unpaired t-test for continuous variables. Nonparametric tests were applied when appropriate. The Cochran-Armitage test was used to asses associations between the seven pain items and the bodily pain scale in SF-36.

Related variables were tested for multicollinearity with Pearson's correlations with a limit of $r \geq 0.60$. Logistic regression analyses were performed with relevant demographic, clinical and health variables as independent variables and caseness of chronic pelvic pain as the dependent variable. The associations were quantified as odds ratios (ORs) with 95\% confidence intervals (95\% CI). We had a large sample from the general population (the NORMS) at our disposal so we were able to adjust for age in the logistic model instead of using matching on age which could possibly lead to bias and loss of efficiency. P-values $<0.05$ were considered statistically significant and two-tailed tests were applied. Data were analysed using the Statistical Package for Social Sciences (SPSS version 14.0).

\section{Results}

Response rate and sample characteristics

Of the 147 eligible CCSs, 7 actively declined (5\%) and 49 (33\%) did not respond to the invitation. After one reminder, a total of $91 \mathrm{CCSs}$ returned completed questionnaires and provided signed informed consent (response rate 62\%). The median age of responders was 62 years (range 37-92) (Table 1).

Table 1 Patient characteristics of 91 responders

\begin{tabular}{lc}
\hline Median age & $62(37-92)$ \\
Median follow-up (months) & $100(66-131)$ \\
FIGO Stage/substage, (N\%) & \\
Ib2 & $13(14 \%)$ \\
IIb & $65(72 \%)$ \\
IIIa/IIIb & $12(13 \%)$ \\
IVa & $1(1 \%)$ \\
Histology & \\
Squamous carcinoma & $80(88 \%)$ \\
Adenocarcinoma & $8(9 \%)$ \\
Adenosquamous carcinoma & $3(3 \%)$ \\
Treatment modalities & \\
Type 1 (EBRT Dose 50/45 Gy + ICRT) & $75(82 \%)$ \\
Type 2 (EBRT Dose $45 / 60$ Gy + ICRT) & $9(10 \%)$ \\
Extended radiation field & $7(8 \%)$ \\
\hline
\end{tabular}

\section{Characteristics of CCSs versus NORMs}

The NORMS were significantly younger than CCSs and we thus adjusted for age. We found no statistically significant differences between CCSs and NORMs concerning partner status and educational level (Table 2). In a multivariate logistic regression analysis, the age-adjusted risk of having lower back pain was significantly higher for CCSs than among the NORMs (OR 3.20, 95\% CI: 2.09-4.91, $p<.001$ ), while the risk of having hip pain was two and a half times higher for CCSs compared to the NORMs (OR 2.60, CI $1.68-4.03, p<.001)$. Daily use of analgesics and hypnotics was also significantly higher in CCSs compared to NORMs (data not shown).

Demographical, physical and mental differences between CCSs with and without pelvic pain

The CCSs' self-rating of chronic pelvic pain is listed in Table 3. Caseness of chronic pelvic pain was defined in 35 (38\%) CCSs. Thirty percent (25/85) of the survivors suffered from lower back pain daily or constantly, and $34 \%$ (26/76) complained of pain during activity daily or constantly. Pain in groins was less often reported. Furthermore, activities of daily living were restricted due to pain in almost one third of the CCSs (Table 3).

Comparisons of CCSs with or without chronic pelvic pain revealed no significant differences in either sociodemographic variables (age, partner-status, educational level, employment status) or treatment related variables (time since diagnosis, FIGO stage, treatment modality). Use of analgesics was significantly higher among patients with chronic pelvic pain $(p=.001)$, while use of medication in general did not differ between the two groups.

Sixty percent of CCSs with chronic pelvic pain complained of severe intestinal problems (especially defecation-urgency and loose or watery stool) and $43 \%$ reported severe bladder problems (especially stress incontinence and urinary urgency). The corresponding proportions among CCSs without such pain were $36 \%$ and $7 \%$ (6/ 56), respectively (Table 4).

The mean levels of anxiety and depression and the prevalence of HADS-defined anxiety and depression caseness were all significantly higher in CCSs with chronic pelvic pain compared to those without. Among CCSs with chronic pelvic pain $8 / 35$ were considered clinically depressed and $14 / 35(40 \%)$ clinically anxious. The corresponding numbers in those without pain were $3 / 56$ and $9 / 56$ ( $p<.001$ for both). The patients were asked about long-term mental complains, and there was no significant difference between the two groups on this item. Concerning QOL, significant differences were observed between CCSs 
Table 2 Distribution of demographic and pain-related factors in CCSs and HUNT-2 NORMs

${ }^{\text {a }}$ Age-adjusted

\begin{tabular}{llcc}
\hline Variables & $\begin{array}{l}\text { CCSs }(N=91) \\
\text { N }(\%)\end{array}$ & $\begin{array}{l}\text { HUNT-2 NORMs }(N=33,054) \\
\text { N }(\%)\end{array}$ & p-value \\
\hline $\begin{array}{llc}\text { Median age (range) } \\
\text { Smoking daily }^{\mathrm{a}}\end{array}$ & $62(37-92)$ & $48(19-98)$ & $<0.001$ \\
Has a partner $^{\mathrm{a}}$ & $34(48)$ & $9517(31)$ & 0.002 \\
Educational level $^{\mathrm{a}}$ & $17(50)$ & $28(53)$ & 0.80 \\
$<9$ years & & & 0.87 \\
$10-12$ years & $34(38)$ & $12428(40)$ & \\
$>13$ years & $38(43)$ & $12439(40)$ & $<0.001$ \\
Lower back pain the previous month $^{\mathrm{a}}$ & $17(19)$ & $6306(20)$ & $<0.001$ \\
Daily lower back pain $^{\mathrm{a}}$ & $47(55)$ & $9069(27)$ & $<0.001$ \\
Hip pain the previous month $^{\mathrm{a}}$ & $25(30)$ & $1817(6)$ & $<0.001$ \\
Daily hip pain $^{\mathrm{a}}$ & $37(45)$ & $7202(22)$ & $1554(5)$ \\
\hline
\end{tabular}

with and without chronic pelvic pain on all SF-36 dimensions (Fig. 1).

Associations between CCS with chronic pelvic pain and various relevant variables

Unadjusted regression analyses of CCSs revealed significant associations between caseness of chronic pelvic pain and use of analgesics, intestinal and bladder morbidity, and depression. In the multivariable logistic regression analysis the use of analgesics and intestinal and bladder morbidity remained significantly associated with chronic pelvic pain in CCSs. (Table 5).

\section{Discussion}

To our knowledge this is the first study of a homogeneous group of CCSs that focuses on self-reported chronic pelvic pain and its associations after radiotherapy. We found that the prevalence of daily lower back pain and hip pain were significantly higher among the CCSs than in the general female population. Using the seven-item case-finding instrument, $38 \%(35 / 91)$ of the CCSs were defined as patients with chronic pelvic pain. There was no statistically significant association between either the presence of pelvic pain and radiation treatment given, or duration of follow-up. When present, chronic pelvic pain was strongly linked to bladder and intestinal morbidity in both univariate and multivariable regression analyses. Barker et al. [25] reported on self-rated bladder and intestinal problems, as well as pain, in a study involving 225 women 36 months after radiotherapy. They found an increase in intestinal and bladder problems after 36 months, but the scores on pelvic pain were at the same level as pre-treatment. However, late-effects after radiation are often progressive and may continue to develop after 3-5 years [26].

The prevalence of pelvic pain in CCSs varies greatly in the literature. There are several possible explanations. Firstly, the results are difficult to compare because of various methods used to assess and analyze pain in different studies. In many studies of CCSs, pain is assessed as a single item in a QOL questionnaire without reference to its location and with varying timeframes (e.g. daily pain, pain during last week or last month). Furthermore, heterogeneous patient samples are studied regarding stage, sample sizes, and treatment modalities. Li et al. [18] reported a prevalence of lower back pain of $47 \%$ in CCSs. However, their sample size was small $(N=28)$ in ovaries removed group), information on radiotherapy was scarce, and they
Table 3 Cervical cancer survivors' self-rating of pain in pelvic region

${ }^{a}$ Activity of daily living

\begin{tabular}{|c|c|c|c|c|c|}
\hline & None & Monthly & Weekly & Daily & Constantly \\
\hline \multicolumn{6}{|c|}{ Proportions of positive ratings (\%) } \\
\hline Lower back pain & $38 / 85(44)$ & $12 / 85(14)$ & $10 / 85(12)$ & $21 / 85(25)$ & $4 / 85(5)$ \\
\hline Hip pain & $45 / 82(55)$ & $8 / 82(10)$ & $11 / 82(13)$ & $15 / 82(18)$ & $3 / 82(4)$ \\
\hline Pain in groins & $62 / 81(77)$ & $4 / 81(5)$ & $7 / 81(9)$ & $6 / 81(7)$ & $2 / 81(2)$ \\
\hline Radiating pain & $54 / 86(63)$ & $4 / 86(5)$ & $8 / 86(9)$ & $17 / 86(20)$ & $3 / 86(3)$ \\
\hline Pain in activity & $31 / 76(41)$ & $11 / 76(14)$ & 8/76 (11) & $22 / 76(29)$ & $4 / 76(5)$ \\
\hline Pain in rest & $48 / 77(62)$ & 4/77 (5) & 8/77 (11) & $11 / 77(14)$ & $6 / 77(8)$ \\
\hline $\mathrm{ADL}^{\mathrm{a}}$ restricted & $52 / 78(68)$ & $2 / 78(3)$ & $1 / 78(1)$ & $16 / 78(20)$ & $6 / 78(8)$ \\
\hline
\end{tabular}


Table 4 Physical and mental symptoms in cervical cancer survivors with and without chronic pelvic-pain

If numbers are smaller than 10 , percentages are not given

\begin{tabular}{lcccc}
\hline & Pain $(N=35)$ & No pain $(N=56)$ & P-value & Total sample $(N=91)$ \\
\hline Severe intestinal problems & $21(60)$ & $20(36)$ & 0.023 & $41(45)$ \\
Severe bladder problems & $15(43)$ & $6^{\mathrm{a}}$ & $<0.001$ & $21(23)$ \\
Caseness of depression & $8^{\mathrm{a}}$ & $3^{\mathrm{a}}$ & 0.017 & $11(13)$ \\
Caseness of anxiety & $14(40)$ & $9^{\mathrm{a}}$ & 0.011 & $23(25)$ \\
Long-term mental complains & $7^{\mathrm{a}}$ & $4^{\mathrm{a}}$ & 0.076 & $11(12)$ \\
\hline
\end{tabular}

asked about pain during the previous 4 weeks without further specification.

Our results were more in line with findings of Bye et al. [17] and Korfage et al.[27] in samples of CCSs. They reported a prevalence of $19-22 \%$ [17, 27] of lower back pain and $18 \%$ of hip pain [17] after radiotherapy. However, their sample sizes were small, and the study groups were heterogeneous with respect to treatment modalities (radiotherapy only or in combination with surgery), stages and/or diagnosis. Furthermore, one of the studies asked about pain during the previous week [27], while no exact timeframe is reported in the other study [17].

In some studies the prevalence of back pain is lower than, or similar to the control group [16-19]. This was not the case in our study, where the risks of having daily lower back pain and hip pain were 3.2 and 2.6 times higher in the CCS group than among the NORMs in the age-adjusted analyses. The reason might be that we analyzed daily pain, in contrary to many studies that enquire about any pain during the previous month. As an occurrence of any recent pain (last 4 weeks) is quite common in the general population [28], our results indicate that more specific reporting might be necessary in order to reveal differences between a patient group and

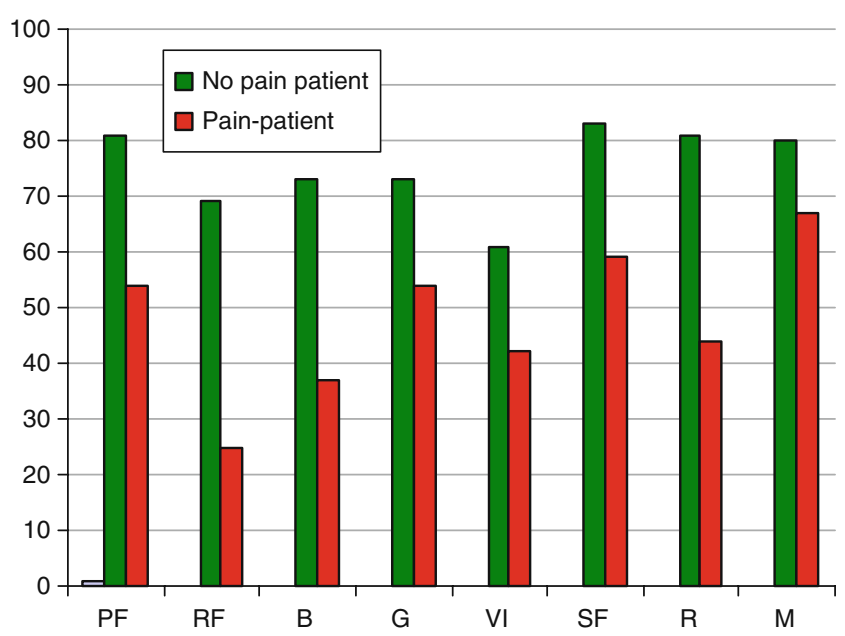

Fig. 1 SF-36 dimensions in CCSs. All p-values $<0.001$ between the CCSs with and without chronic pelvic pain. $P F$ physical functioning, $R F$ role function, $B P$ bodily pain, $G H$ general health, $V I$ vitality, $S F$ social functioning, $R E$ role emotional, $M H$ mental health the general population. In a Norwegian population study $(N=1,912)$, the prevalence of chronic lower back pain among participating women was $14 \%$, with no further information regarding frequency of the pain reported [29]. The response rate was low (49\%) compared to the response rate in our control group (76\%). In our study, $27 \%$ of the NORMs reported lower back pain during the previous month; however, only $6 \%$ of NORMs had pain on a daily basis. Hence, pain must be specified within a timeframe in order to make comparisons possible.

Several studies of gynaecological cancer patients and breast cancer patients reporting on pain indicate that radiotherapy is more associated with long-term sequelae of pain than surgery and chemotherapy [3, 4, 30-33]. The bony structures of the pelvis lie in close proximity to the uterine cervix. Therefore, these structures, as well as the vagina, the bladder and the intestines will be affected by irradiation of varying intensity. The patients in this study were treated by conformal radiotherapy, and adjacent tissue received higher doses of radiation than today, since we now use a technique called intensity-modulation radiation therapy (IMRT) [34, 35]. With the IMRT approach, higher and more effective radiation doses can safely be delivered to tumors with fewer side effects compared with conventional radiotherapy techniques. However, even though the radiation regimen has changed since the women of this study were treated, several audits and clinical studies suggest that the success of combining radiotherapy with chemotherapy comes at a price in terms of late morbidity. The effect of irradiation on bone tissue is not completely understood; however, damage occurs at the bone matrix and at the cellular as well as the vascular level $[3,4,36,37]$. This may lead to atrophy and further to reduction of the functional components of the bony structure, making it more susceptible to insufficiency fractures at weight-bearing areas. In 1996, Blomlie et al. [2] studied prospectively with Magnetic Resonance Imaging (MRI) cervical cancer patients treated with radiotherapy at the Norwegian Radium Hospital. Sixteen of 18 patients showed findings of insufficiency fractures within 12 months, whereof $21 \%$ of the lesions healed during the observation period of 30 months. Recent studies have reported the cumulative 5-year incidence of insufficiency fractures diagnosed by MRI, to be $8.2-19.7 \%$ after pelvic 
Table 5 Univariate and multivariate logistic regression analyses of independent variables and caseness of chronic pelvic pain in CCSs as dependent variable (without pain $=$ reference)

${ }^{\text {a }}$ Anxiety was not included in the analyses due to multicolinearity

\begin{tabular}{|c|c|c|c|c|c|c|}
\hline \multirow[t]{2}{*}{ Variables } & \multicolumn{3}{|c|}{ Univariate } & \multicolumn{3}{|c|}{ Multivariate } \\
\hline & OR & $95 \% \mathrm{CI}$ & p-value & OR & $95 \% \mathrm{CI}$ & p-value \\
\hline Employed (ref) & 1.00 & & & & & \\
\hline Unemployed /pensioned & 0.52 & $0.20-1.38$ & 0.16 & & & \\
\hline Long-term mental complains & 0.32 & $0.85-11.83$ & 0.87 & & & \\
\hline Psychotropics & 2.18 & $0.33-14.36$ & 0.42 & & & \\
\hline Analgesics & 4.93 & $1.86-13.06$ & 0.001 & 3.77 & $1.26-11.27$ & 0.02 \\
\hline Bladder/intestinal problems & 3.59 & $1.45-8.88$ & 0.006 & 3.39 & $1.18-8.96$ & 0.01 \\
\hline Depression $^{\mathrm{a}}$ & 4.94 & $1.21-20.17$ & 0.026 & 2.43 & $0.48-12.35$ & 0.77 \\
\hline
\end{tabular}

radiotherapy in gynaecologic cancer patients [3, 36, 37]. Though pain related to insufficiency fractures may be severe in some patients, the symptoms are usually mild, even asymptomatic [4, 36], and they cannot explain the patient-reported prevalence of back pain extracted from QOL studies of CCSs. Furthermore, if treated properly (analgesics and rest), symptoms and MRI findings usually disappear within 6-12 months after diagnosis [38]. We did not examine our patients with radiographic examinations, hence we do not know if any of these women suffered from pelvic insufficiency fractures.

Chronic pelvic pain was associated with both intestinal and bladder problems in the analyses. Individual variations in the patients' response to, and complications after treatment have traditionally been explained as resulting from either disease-related variables (stage of disease), clinical health status (performance status, comorbid conditions), or socio-demographic characteristics [39]. However, within the last decade there has been an increasing interest in studies indicating that normal tissue radiosensitivity and cancer related symptoms can be predicted from individual genetic profiles [40, 41]. Despite a small number of survivors, our results indicate that approximately one third experience long-term side-effects, involving intestinal and bladder problems, as well as pelvic pain. Maybe these patients were more susceptible to radiotherapy than the other two thirds of the survivors?

CCSs with pelvic pain scored significantly lower on all dimensions of the SF-36 compared to those without pelvic pain. However, one has to be aware that bodily pain is one of the items in the PCS scale and thus influence the overall score on SF-36. The findings are consistent with reports from studies of breast and gynaecologic cancer survivors showing that pain may have a significant impact on QOL and day-to-day well-being of the survivors [42].

Strengths and limitations

A major strength of this study is that we considered a group of CCSs that was homogeneous with respect to treatment modality (radiotherapy) and time since diagnosis ( $\geq 5$ years). We used standardized instruments covering QOL and anxiety and depression. In addition, we were able to adjust for age and compare our CCSs with a normative sample using logistic regression models. Furthermore, clinical data on the non-participating CCSs were available indicating that this group did not differ significantly from the study group, thus limiting a possible selection bias.

A weakness of our study is the use of ad hoc items to assess for chronic pelvic pain. We were unable to identify case finding screening tools, and these items were based on clinical experience and syndrome definitions. While further work is needed to validate these findings in other populations, the questions used in this study had promising psychometric correlations, and can help guide clinical assessments and serve as a basis for future studies. We also had a small sample size with a considerable risk of type II statistical error implying that some of our results could be statistically significant with larger sample size and thus increased statistical power. Since CCSs were assessed cross-sectionally, we have no information concerning pre-morbid physical and mental status that could have influenced outcome variables like pain, anxiety, depression, and bladder and intestinal complaints. Another weakness is that we did not examine the patients with biopsies or radiographic examinations in order to detect pathological differences due to radiation sequelae between the groups with and without pelvic pain. The preferable method would have been to physically examine all the women at the Radium Hospital. However, it would involve travelling for the majority of these women who were elderly, and only a few lived in Oslo, so this alternative was not feasible.

\section{Conclusion}

We have shown that the CCS have a higher prevalence of pain in lower back and hips than women from the general population, which might be due to late effects of radiation. 
Pain after pelvic radiotherapy may negatively affect rehabilitation, increase suffering, and negatively influence QOL. Therefore, future research should focus on methods for preventing morbidity of the pelvic organs without compromising tumour control. Furthermore, a thorough evaluation of pelvic pain is important; both to establish the appropriate diagnosis and to rule out cancer recurrence in the follow-up of CCSs. Management of chronic pain in CCSs should be optimized by a multidisciplinary approach involving the use of analgesics, physical therapy, interventional procedures, and psychosocial interventions. In addition, as some patients seem to be more susceptible to radiation therapy in terms of developing long-term mental and physical morbidity, predicting an individual's risk of radiation-induced normal tissue complications prior to cancer therapy should be a priority in clinical radiobiology studies.

Acknowledgments The authors would like to thank Karin Skogsfjord and Taran Hellebust for their assistance in data collection. The NordTrøndelag Health Study (The HUNT Study) contributed with the normative data material.

Contribution of authorship Vistad contributed in acquisition, analysis and interpretation of data. She drafted and revised the manuscript, and gave final approval of the version to be published. Cvancarova contributed in analysis and interpretation of data. She revised the manuscript, and gave final approval of the version to be published. Kristensen contributed in acquisition of data. He revised the manuscript, and gave final approval of the version to be published. Fosså contributed in interpretation of data. She revised the manuscript, and gave final approval of the version to be published.

Disclosure of interest We hereby state that there are no conflicts of interest for any of the authors.

Funding I. Vistad received financial support by Sorlandet Hospital HF

Open Access This article is distributed under the terms of the Creative Commons Attribution Noncommercial License which permits any noncommercial use, distribution, and reproduction in any medium, provided the original author(s) and source are credited.

\section{References}

1. Levy MH, Chwistek M, Mehta RS. Management of chronic pain in cancer survivors. Cancer J. 2008;14(6):401-9.

2. Blomlie V, Rofstad EK, Talle K, Sundfor K, Winderen M, Lien HH. Incidence of radiation-induced insufficiency fractures of the female pelvis: evaluation with MR imaging. AJR Am J Roentgenol. 1996;167(5):1205-10.

3. Baxter NN, Habermann EB, Tepper JE, Durham SB, Virnig BA. Risk of pelvic fractures in older women following pelvic irradiation. JAMA. 2005;294(20):2587-93.

4. Kwon JW, Huh SJ, Yoon YC, Choi SH, Jung JY, Oh D, et al. Pelvic bone complications after radiation therapy of uterine cervical cancer: evaluation with MRI. AJR Am J Roentgenol. 2008;191(4):987-94.

5. Vistad I, Kristensen GB, Fossa SD, Dahl AA, Morkrid L. Intestinal malabsorption in long-term survivors of cervical cancer treated with radiotherapy. Int J Radiat Oncol Biol Phys. 2009;73 (4):1141-7.

6. Vistad I, Cvancarova M, Fossa SD, Kristensen GB. Postradiotherapy morbidity in long-term survivors after locally advanced cervical cancer: how well do physicians' assessments agree with those of their patients? Int J Radiat Oncol Biol Phys. 2008;71 (5):1335-42.

7. Bergmark K, Avall-Lundqvist E, Dickman PW, Henningsohn L, Steineck G. Patient-rating of distressful symptoms after treatment for early cervical cancer. Acta Obstet Gynecol Scand. 2002;81 (5):443-50.

8. Bismar MM, Sinicrope FA. Radiation enteritis. Curr Gastroenterol Rep. 2002;4(5):361-5.

9. Cancer pain. Wall and Melzack's Textbook of Pain. 5 ed. Philadelphia: Elsevier/Churchill Livingstone; 2005. p. 1120.

10. Visceral and other syndromes of the trunk apart from spinal and radicular pain. In: Merskey H, Bogduk N, editors. Classification of Chronic Pain. 2 ed. Seattle: IASP Press; 1994. p. 170.

11. Kaasa S, Loge JH, Knobel H, Jordhoy MS, Brenne E. Fatigue. Measures and relation to pain. Acta Anaesthesiol Scand. 1999;43 (9):939-47.

12. Bruera E, Kim HN. Cancer pain. JAMA. 2003;290(18):2476-9.

13. Delaney A, Fleetwood-Walker SM, Colvin LA, Fallon M. Translational medicine: cancer pain mechanisms and management. Br J Anaesth. 2008;101(1):87-94.

14. Vahdaninia M, Omidvari S, Montazeri A. What do predict anxiety and depression in breast cancer patients? A follow-up study. Soc Psychiatry Psychiatr Epidemiol 2009 May 21.

15. Matulonis UA, Kornblith A, Lee H, Bryan J, Gibson C, Wells C, et al. Long-term adjustment of early-stage ovarian cancer survivors. Int J Gynecol Cancer. 2008;18(6):1183-93.

16. Klee M, Thranov I, Machin PD. The patients' perspective on physical symptoms after radiotherapy for cervical cancer. Gynecol Oncol. 2000;76(1):14-23.

17. Bye A, Trope C, Loge JH, Hjermstad M, Kaasa S. Health-related quality of life and occurrence of intestinal side effects after pelvic radiotherapy - evaluation of long-term effects of diagnosis and treatment. Acta Oncol. 2000;39(2):173-80.

18. Li C, Samsioe G, Iosif C. Quality of life in long-term survivors of cervical cancer. Maturitas. 1999;32(2):95-102.

19. Rannestad T, Skjeldestad FE. Pain and quality of life among longterm gynecological cancer survivors: a population-based casecontrol study. Acta Obstet Gynecol Scand. 2007;86(12):1510-6.

20. Davidson SE, Burns MP, Routledge JA, Swindell R, Bentzen SM, West CM. Assessment of morbidity in carcinoma of the cervix: a comparison of the LENT SOMA scales and the Franco-Italian glossary. Radiother Oncol. 2003;69(2):195-200.

21. Zigmond AS, Snaith RP. The hospital anxiety and depression scale. Acta Psychiatr Scand. 1983;67(6):361-70.

22. Bjelland I, Dahl AA, Haug TT, Neckelmann D. The validity of the hospital anxiety and depression scale. An updated literature review. J Psychosom Res. 2002;52(2):69-77.

23. Ware JE Jr, Snow KK, Kosinski M, Gandek B. SF-36 Health Survey: Manual and Interpretation Guide. Boston, Massachusetts, QualityMetric Incorporated; 2000.

24. Holmen J, Midthjell K, Kruger O, Langhammer A. The NordTrøndelag Health Study 1995-97 (HUNT 2): objectives, contents, methods and participation. Nor Epidemiol. 2003;13(1):19-32.

25. Barker CL, Routledge JA, Farnell DJ, Swindell R, Davidson SE. The impact of radiotherapy late effects on quality of life in gynaecological cancer patients. Br J Cancer. 2009;100(10):155865. 
26. Miller KD, Triano LR. Medical issues in cancer survivors-a review. Cancer J. 2008;14(6):375-87.

27. Korfage IJ, Essink-Bot ML, Mols F, van de Poll-Franse LV, Kruitwagen R, van Ballegooijen M. Health-related quality of life in cervical cancer survivors: a population-based survey. Int $\mathrm{J}$ Radiat Oncol Biol Phys. 2009;73(5):1501-9.

28. Thomas E, Peat G, Harris L, Wilkie R, Croft PR. The prevalence of pain and pain interference in a general population of older adults: cross-sectional findings from the North Staffordshire Osteoarthritis Project (NorStOP). Pain. 2004;110(1-2):361-8.

29. Rustoen T, Wahl AK, Hanestad BR, Lerdal A, Paul S, Miaskowski C. Prevalence and characteristics of chronic pain in the general Norwegian population. Eur J Pain. 2004;8(6):555-65.

30. Greimel ER, Winter R, Kapp KS, Haas J. Quality of life and sexual functioning after cervical cancer treatment: a long-term follow-up study. Psychooncology. 2009;18(5):476-82.

31. Gulluoglu BM, Cingi A, Cakir T, Gercek A, Barlas A, Eti Z. Factors related to post-treatment chronic pain in breast cancer survivors: the interference of pain with life functions. Int J Fertil Womens Med. 2006;51(2):75-82.

32. Ishiyama H, Niino K, Hosoya $T$, Hayakawa K. Results of a questionnaire survey for symptom of late complications caused by radiotherapy in breast conserving therapy. Breast Cancer. 2006;13 (2):197-201.

33. Peuckmann V, Ekholm O, Rasmussen NK, Groenvold M, Christiansen P, Moller S, et al. Chronic pain and other sequelae in long-term breast cancer survivors: nationwide survey in Denmark. Eur J Pain. 2009;13(5):478-85.

34. Beriwal S, Gan GN, Heron DE, Selvaraj RN, Kim H, Lalonde R, et al. Early clinical outcome with concurrent chemotherapy and extended-field, intensity-modulated radiotherapy for cervical cancer. Int J Radiat Oncol Biol Phys. 2007;68(1):166-71.

35. Chen MF, Tseng CJ, Tseng CC, Kuo YC, Yu CY, Chen WC. Clinical outcome in posthysterectomy cervical cancer patients treated with concurrent Cisplatin and intensity-modulated pelvic radiotherapy: comparison with conventional radiotherapy. Int $\mathrm{J}$ Radiat Oncol Biol Phys. 2007;67(5):1438-44.

36. Ikushima H, Osaki K, Furutani S, Yamashita K, Kishida Y, Kudoh $\mathrm{T}$, et al. Pelvic bone complications following radiation therapy of gynecologic malignancies: clinical evaluation of radiation-induced pelvic insufficiency fractures. Gynecol Oncol. 2006;103(3):1100-4.

37. Oh D, Huh SJ, Nam H, Park W, Han Y, Lim dH, et al. Pelvic insufficiency fracture after pelvic radiotherapy for cervical cancer: analysis of risk factors. Int J Radiat Oncol Biol Phys. 2008;70 (4):1183-8.

38. Gillette EL, Mahler PA, Powers BE, Gillette SM, Vujaskovic Z. Late radiation injury to muscle and peripheral nerves. Int J Radiat Oncol Biol Phys. 1995;31(5):1309-18.

39. Reyes-Gibby CC, Wu X, Spitz M, Kurzrock R, Fisch M, Bruera E, et al. Molecular epidemiology, cancer-related symptoms, and cytokines pathway. Lancet Oncol. 2008;9(8):777-85.

40. Casso D, Buist DS, Taplin S. Quality of life of 5-10 year breast cancer survivors diagnosed between age 40 and 49 . Health Qual Life Outcomes. 2004;2:25.

41. Dow KH, Ferrell BR, Leigh S, Ly J, Gulasekaram P. An evaluation of the quality of life among long-term survivors of breast cancer. Breast Cancer Res Treat. 1996;39(3):261-73.

42. Sullivan MJ, Lynch ME, Clark AJ. Dimensions of catastrophic thinking associated with pain experience and disability in patients with neuropathic pain conditions. Pain. 2005;113(3):310-5. 